\title{
Effects of school-based physical activity on mathematics performance in children: a systematic review
}

\author{
S. Sneck ${ }^{1,2^{*}} \mathbb{D}$, H. Viholainen ${ }^{3}$, H. Syväoja ${ }^{1}$, A. Kankaapää ${ }^{1}$, H. Hakonen ${ }^{1}$, A.-M. Poikkeus ${ }^{4}$ and T. Tammelin ${ }^{1}$
}

\begin{abstract}
Background: The benefits of physical activity (PA) on children's health and wellbeing are well established. However, the benefits of PA on academic performance and particularly on mathematics performance warrant systematic analysis. Mathematics is one of the core subjects in school education globally.

Methods: We systematically searched, analysed and synthesized the literature on the effects of school-based PA interventions on mathematics performance in children aged 4-16. A total of 29 studies consisting of randomised trials and other interventions with control groups were identified through a systematic search, and 11 of them provided sufficient data and appropriate design for a meta-analysis.

Results: Of the 29 studies involving 11,264 participants, positive overall effects of a PA intervention on mathematics performance were found in 13 studies (45\%) and neutral overall effects in 15 studies (52\%). Only one study reported a significant negative result for a subgroup of children in the first half of the intervention. In a risk-of-bias assessment, 12 studies had low, 17 moderate, and none had a high risk of bias. The meta-analysis of 11 studies suggested an overall small positive effect $(E S=0.23)$ of the interventions. Only one study in the meta-analysis indicated a negative effect in one of the intervention groups.

Conclusions: Adding PA to the school day may enhance children's mathematics performance or has no negative effects on performance. Several types of PA interventions can be recommended to be added to the school day.
\end{abstract}

Keywords: Physical activity, Mathematics performance, Intervention

\section{Introduction}

Physical activity (PA) is defined as any bodily movement produced by skeletal muscles that results in energy expenditure [1]. There is extensive evidence indicating that participating in PA is associated with a variety of benefits for children and adolescents, including better physical health $[1,2]$ better cognitive and mental health [3], a more positive physical self-concept [4], enhanced global self-esteem [4], and improved academic outcomes [5, 6]. Furthermore, higher PA levels in adolescence have been shown to be positively related to the number of years of post-compulsory education and long-term labour market

\footnotetext{
* Correspondence: sirpa.sneck@likes.fi

${ }^{1}$ LIKES Research Centre for Physical Activity and Health, Rautpohjankatu 8, 40700 Jyväskylä, Finland

${ }^{2}$ Faculty of Education, University of Oulu, Oulu, Finland

Full list of author information is available at the end of the article
}

outcomes [7], which translate into both personal and societal benefits.

Worryingly, however, increasing numbers of schoolaged children spend a high proportion of their time in sedentary activities, both at school and during their free time [8]. Physical education (PE) lessons tend to constitute the only occasions providing organized PA during the school day, and it is argued that the role of PA during the school day has not been sufficiently promoted in most countries $[9,10]$. Somewhat different criteria are used internationally to measure PA, but a common finding is that the amount of PA during the school day is typically small. Globally, less than $20 \%$ of children on average are physically active for the recommended 60 or more minutes per day [11, 12]. Less than half of children in the US meet the guidelines of $30 \mathrm{~min}$ of PA during a school day [13]. 
Childhood inactivity has been shown to have detrimental effects not only on children's physical and mental health but possibly also on their cognitive and academic performance [5, 14]. To respond to the current low levels of PA among children, interventions have been conducted in the past two decades in several European countries, North America and Australia to increase the amount of PA during the school day. The interventions have not only modified children's cardiovascular disease risk factors [15] but increasing evidence indicates that PA interventions do not have negative effects on children's academic performance, cognitive function or on-task behaviour and may even benefit academic performance, particularly in mathematics $[6,16,17]$.

Several mechanisms or mediating factors may underlie the effects of PA on academic performance among children. Human and non-human brain research suggests that PA has both acute and lasting effects on the structure and function of the central nervous system, and PA is hypothesized to promote children's development via effects on brain systems that underlie cognition and behaviour [18-20]. There is evidence indicating that PA affects cognition by, for example, influencing the management of energy metabolism and synaptic plasticity [21].

Recent studies support the assumption that PA may affect executive functions [22, 23]. Executive functions involve inhibition, working memory and cognitive flexibility [24], which in turn have been found to be associated with achievement in both reading and mathematics [25]. Several intervention studies have indicated that PA during the school day is positively associated with increased attention and time-on-task [26, 27]. It is also acknowledged that PA can improve children's cognitive, emotional and behavioural school engagement [28] and thus affect achievement positively. However, the findings on links between PA interventions and cognitive performance in children are still relatively rare and inconsistent $[6,16,29]$.

Children's motor development and related cognitive learning may be another mediating mechanism explaining the positive effects of PA on academic performance. This is suggested by studies showing that children's physical growth, motor development and cognitive development are closely linked [30-32]. Many cognitive skills, such as visuospatial skills, rapid automatized naming and memory skills, contribute to arithmetic learning $[33,34]$. Peng and colleagues [35] suggest that deficits in processing speed and working memory are across-age salient cognitive markers of mathematical difficulties. Memory and processing skills might be influenced when PA is added to mathematics instruction or to the school day. For instance, Mullender-Wijnsma and colleagues $[36,37]$ used repetition and memorization strategies to promote numerical processing speed in their PA intervention study.
It has also been demonstrated that emotional experiences are linked to mathematical achievement [38]. Sorvo and colleagues [39] reported that children as young as eight may experience anxiety about mathematics-related situations and about failure in mathematics. Therefore, including PA in mathematics lessons may affect emotional experiences and thus benefit children's mathematics performance.

Mathematics is one of the core curriculum subjects, and the role of mathematical skills in modern technological societies is unquestionable [40]. However, in the past decade, concerns about children's declining interest and performance in mathematics have been expressed internationally [41-43]. Children's low interest in mathematics may be partially because mathematics is a subject in which students are reported to spend up to $76 \%$ of lesson time in sedentary work [10]. If increasing the amount of PA during math lessons or the school day proves to yield higher engagement, interest and enjoyment and in turn contributes to better mathematics performance, a strong argument could be made to introduce more daily PA in schools. To the best of our knowledge, reviews investigating the effects of schoolbased PA on academic performance in general have been conducted, but this is the first review specifically investigating the effects of PA on mathematics performance.

The aim of this systematic review and meta-analysis is to address the following questions: (a) Do school-based PA interventions have an effect on children's mathematics performance? (b) What are the characteristics of PA interventions with positive effects on math performance?

\section{Methods}

We followed the Preferred Reporting Items for Systematic Reviews and Meta-Analysis (PRISMA) guidelines in conducting and reporting on this systematic review. The study selection flow is presented in Fig. 1.

\section{Eligibility criteria}

We used the population, intervention, comparison, outcomes (PICO) model to set the eligibility criteria for the systematic review [44]. Population: Intervention participants were 4-16 years old. Studies investigating subgroups of children were accepted (e.g. overweight children). Intervention: Controlled trials or other pretest-posttest experiments were included. Both betweengroup and within-subject designs were accepted. The studies investigated the effects of added school-based (or preschool-based) PA on children's mathematics performance. PA took place immediately before, during or after school lessons or at break time or was in the form of PE lessons. Comparison: Only studies with baseline measurements and control groups were included. Outcomes: Studies using scores from standardized or norm- 


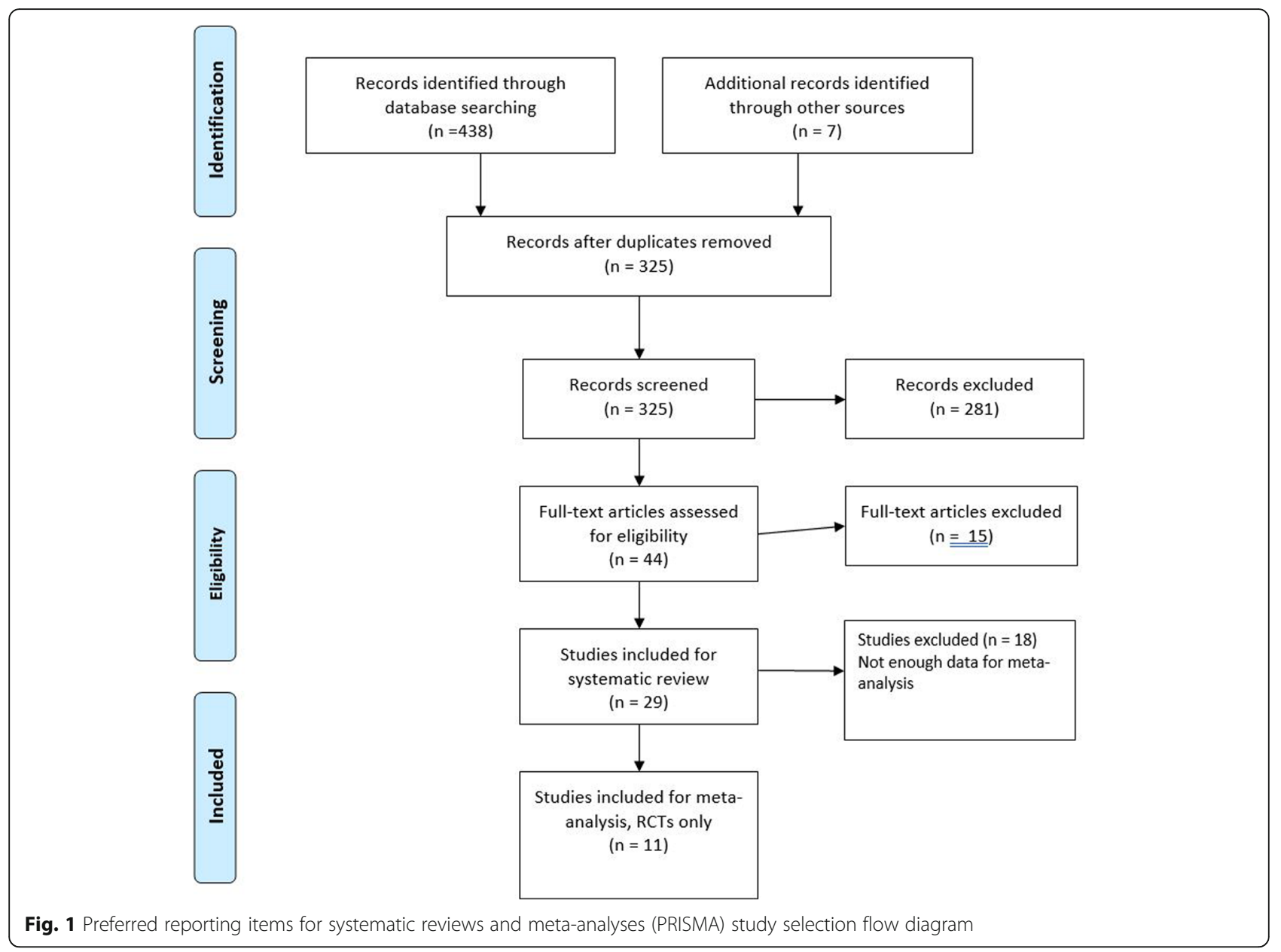

referenced, basic arithmetic or curriculum-based mathematics tests were accepted. Types of study reports: Peer-reviewed full-text academic journal articles published in English between January 2000 and November 2018 were examined.

\section{Study selection and data collection}

We searched ProQuest, PsycINFO, SPORTDiscus and Medline in January 2018 for studies to include in this review. The following search terms were employed in Medline: ('math"' or 'arithmetic"' or 'numeracy') AND ('physical activit"' or 'exercise') AND ('school"'). The same keywords, slightly modified to adapt to those typical for the search engine, were used in the other databases. An additional search was completed in November 2018 using the same strategy. The complete search strategy details are presented in detail in Additional file 1.

Altogether, we identified 438 studies through the database searches; 325 were retained after removing $113 \mathrm{du}$ plicates. An additional seven studies meeting the inclusion criteria were found through a search of previous systematic reviews on related topics $[6,45]$ or through searching the reference lists of studies already included. The titles and abstracts of the remaining 325 articles were screened by SS, HV, A-MP and TT. Disagreements were resolved through discussion. Based on consensus decisions, 44 full-text articles were included in the next step. This involved an examination of the full-text articles by SS and HS before finally selecting 29 full-text articles. See the flow diagram in Fig. 1. The main reasons for excluding studies during the process were: 1) No baseline measurement for math performance was conducted 2) The interventions did not have a control group 3) Math performance was measured by teachers' report cards. Detailed data from the included articles were extracted into Microsoft Excel by SS and HS (Table 1). Where available, pretest-posttest group means were collected to conduct a meta-analysis. Ten original authors were contacted by e-mail to acquire missing data for the analysis. The original authors were given three weeks to reply and were reminded once about the request. Supplementary data were received from three authors. Sufficient data for a full metaanalysis were available for 11 studies. 


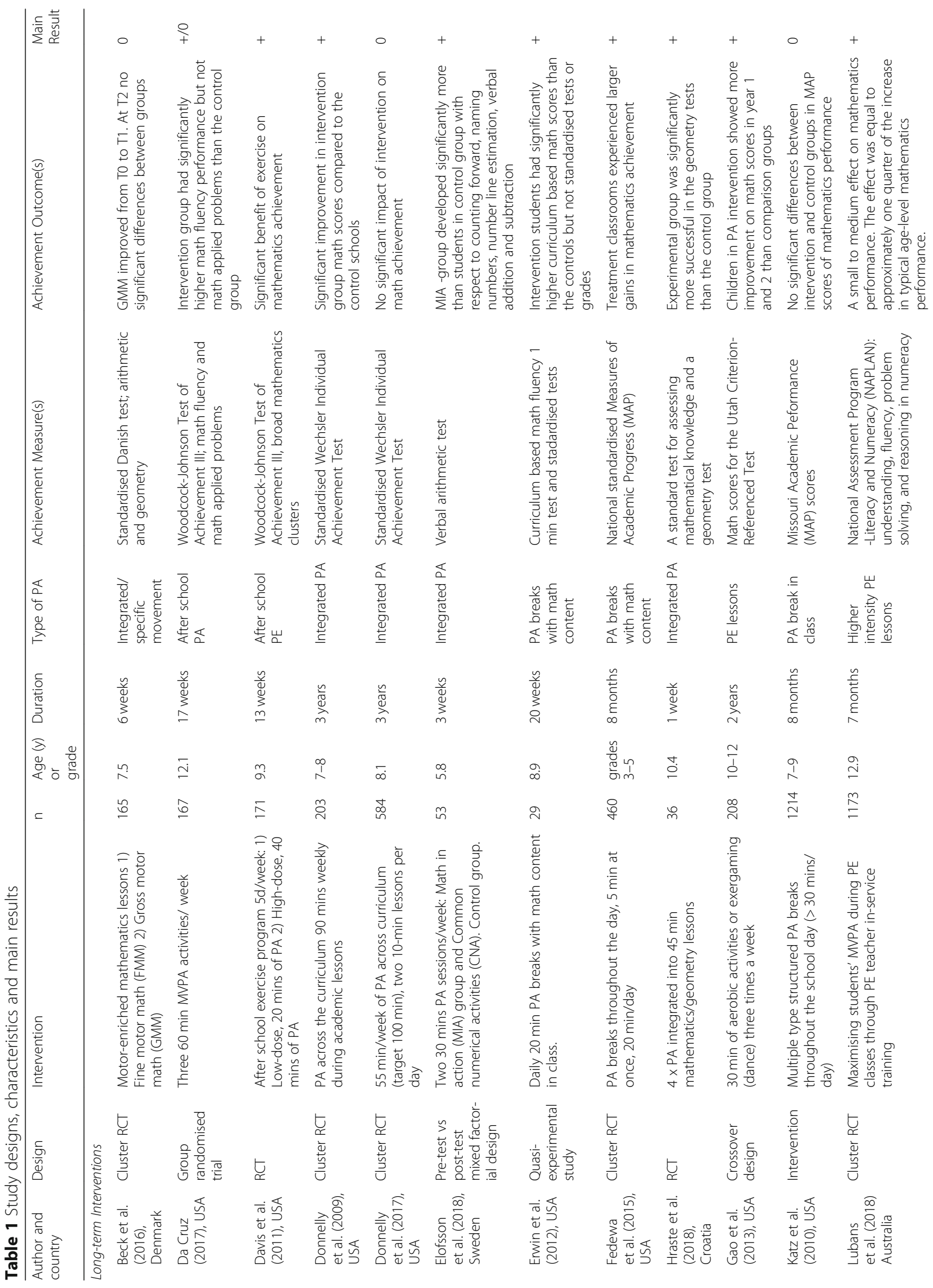




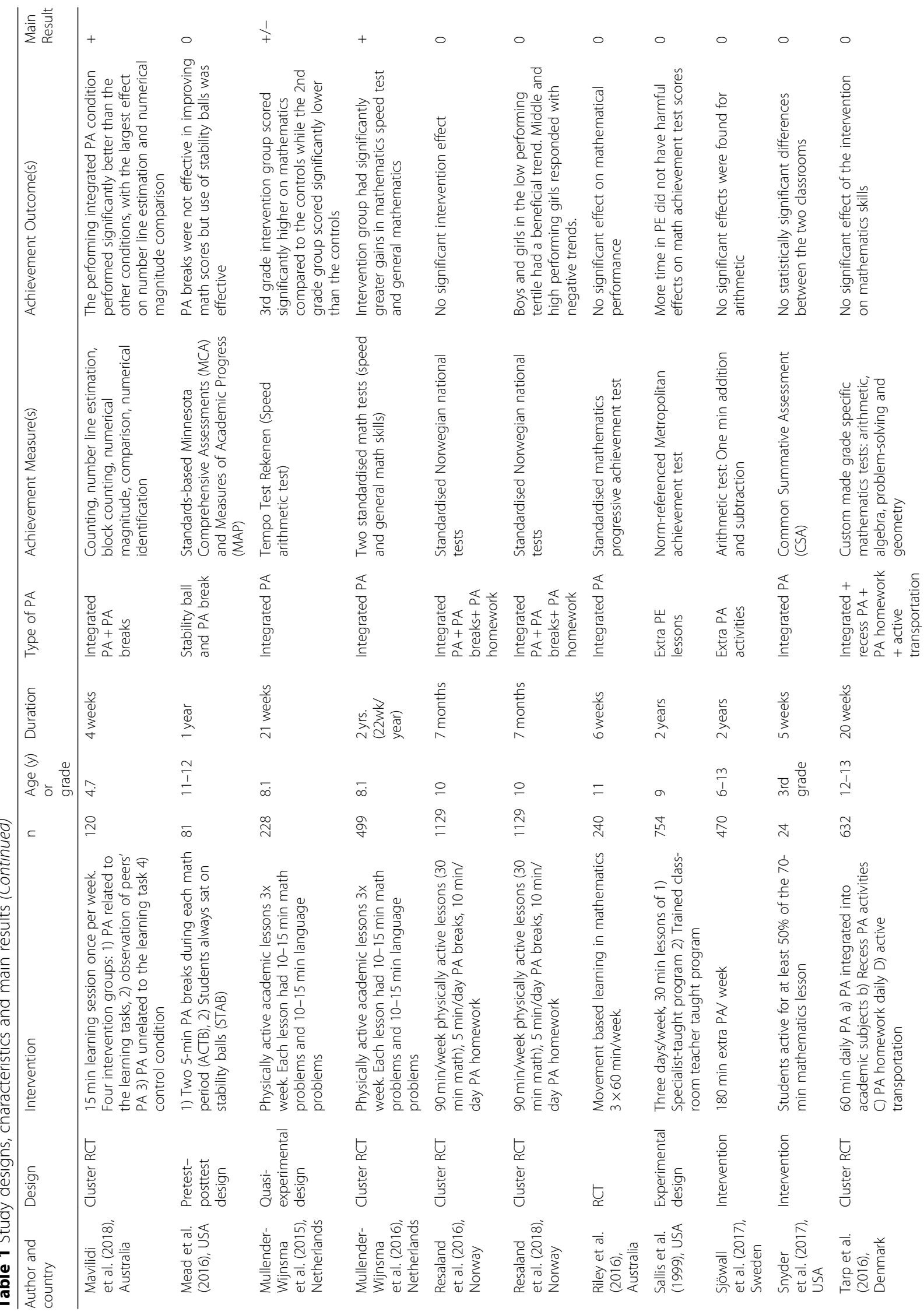




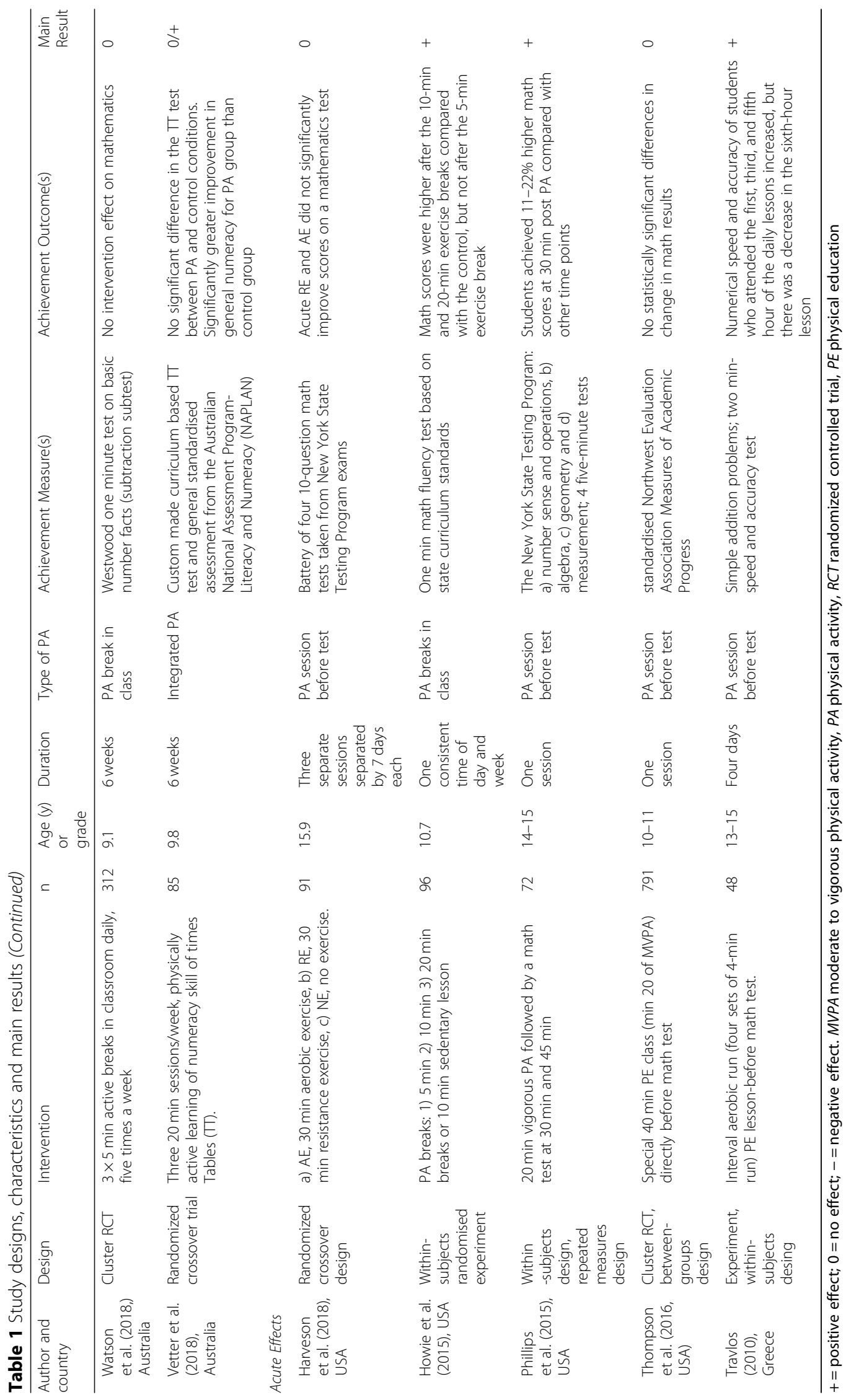




\section{Risk-of-Bias assessment}

A risk-of-bias assessment of the final sample of 29 studies was conducted using combined, modified criteria previously used by Lonsdale [46] and Van Sluijs [47] and following the guidelines of the Cochrane Handbook for Systematic Reviews of Interventions [44]. Some slight modifications were made to the risk assessment criteria to adapt to experiments conducted in the fields of education and psychology. It is acknowledged that experimental and quasi-experimental designs to evaluate the effects of policy and programs need to have adequate statistical power to detect meaningful size impacts. Therefore, the criterion of power calculation was added to the assessment [48]. Each study received '0' (does not meet the criterion) or ' 1 ' (meets the criterion) for each criterion based on an analysis of the reporting in the original article.

\section{Meta-analysis procedures}

Only randomized controlled trials were included in the meta-analysis to ensure high-quality interpretation [44]. Effect size (ES) estimates were calculated using Cohen's d. Only post-intervention (not mid-intervention) mean (M) values were used in the analysis. For between-group designs, Cohen's d was calculated as follows:

$$
d=\frac{\left(M_{\text {treatment }}^{t 2}-M_{\text {treatment }}^{t 1}\right)-\left(M_{\text {control }}^{t 2}-M_{\text {control }}^{t 1}\right)}{S D_{\text {pooled }}}
$$

where $M_{\text {treatment }}^{t 1}, M_{\text {treatment }}^{t 2}, M_{\text {control }}^{t 1}$ and $M_{\text {control }}^{t 2}$ are the baseline (t1) and post-intervention (t2) means in the treatment and control groups, and $S D_{\text {pooled }}$ is the pooled standard deviation.

The I2 statistic was calculated [49] to evaluate heterogeneity among the studies, and the following values were used for interpretation: $<30 \%$, mild; $30-50 \%$, moderate and $>50 \%$, high heterogeneity [50]. Pooled ES estimates and $95 \%$ confidence intervals were calculated using a random effect model. The ES estimates and confidence intervals of individual studies and pooled estimates are presented in Fig. 2. A decision was made to consider ES $\geq 0.8$ large; $\geq 0.5$ medium and $\geq 0.2$ small [51, 52]. As heterogeneity was found to be large in the sample of 11 studies, a moderator analysis was performed. Metaregression analyses were conducted to assess the relationship between ES estimates and the following studylevel variables: participants' age and duration and type of intervention. Further analyses were conducted using the statistical software package R (version 3.4.3). The 95\% confidence intervals for the ES of individual studies, heterogeneity and meta-regression estimates were calculated using the MBESS package [53].

\section{Results}

\section{Systematic review of study characteristics}

A total of 29 intervention studies were included in the systematic review. A descriptive summary of the characteristics of the reviewed studies is presented in Table 1. The countries of origin of the studies are as follows: USA [14], Australia [5], Denmark [2], the Netherlands [2], Norway [2], Sweden [2], Croatia [1] and Greece [1]. The participants ranged in age from 4.7 to 16 years old. Two of the studies were conducted in a preschool setting $[54,55]$. The total number of participants in the intervention and control groups ranged from 29 to 1214 children $[56,57]$. The intervention participants comprised 11,264 children.

Standardized or national-level mathematics tests were employed in 22 studies to measure mathematics learning outcomes. The remaining studies employed custommade tests that typically assessed basic arithmetic skills or were based on local age-level curriculum goals. Many studies employed more than one type of mathematics test $[36,56,58-61]$. The length of the interventions varied between 1 week [62] and 3 years [63, 64]. Of the 29 studies, 5 investigated the acute effects of PA interventions, that is, a short PA session lasting 5-40 min took place right before a mathematics test.

The content of the interventions varied greatly. In 11 studies, PA was integrated into mathematics lessons and included curriculum-based mathematics goals $[10,36$, $37,40,54,55,62-66]$. Positive results were reported in 5 (45\%) of these 11 studies [36, 54, 55, 62, 63]. Only one study reported significant negative results [37] for a subgroup of 8-year old children in the first half of the intervention. Two studies reported partly positive and partly neutral results $[40,66]$.

In five studies, the intervention consisted of extra PE lessons, more intense PE lessons or other extra teacherled PA during the school day [58, 67-70]. Three out of five interventions showed positive results on mathematics performance [68-70], while one study reported partly positive and partly neutral results [58]. One of the studies reported neutral effects [67]. It is noteworthy that some of these studies involved subgroups; da Cruz [58] studied only girls, Gao and colleagues [70] studied only Latino children and Davis and colleagues [68] studied only overweight children.

Five intervention studies involved short PA breaks during lessons or in the middle of the school day $[56,57,59,71,72]$. The length of PA breaks varied between $5 \mathrm{~min}$ and $20 \mathrm{~min}$, and there could be several breaks during a day. Two of the five studies indicated positive results $[56,71]$ and the rest reported neutral effects.

The remaining three long-term interventions used a combination of various types of PA $[60,73,74]$. The 


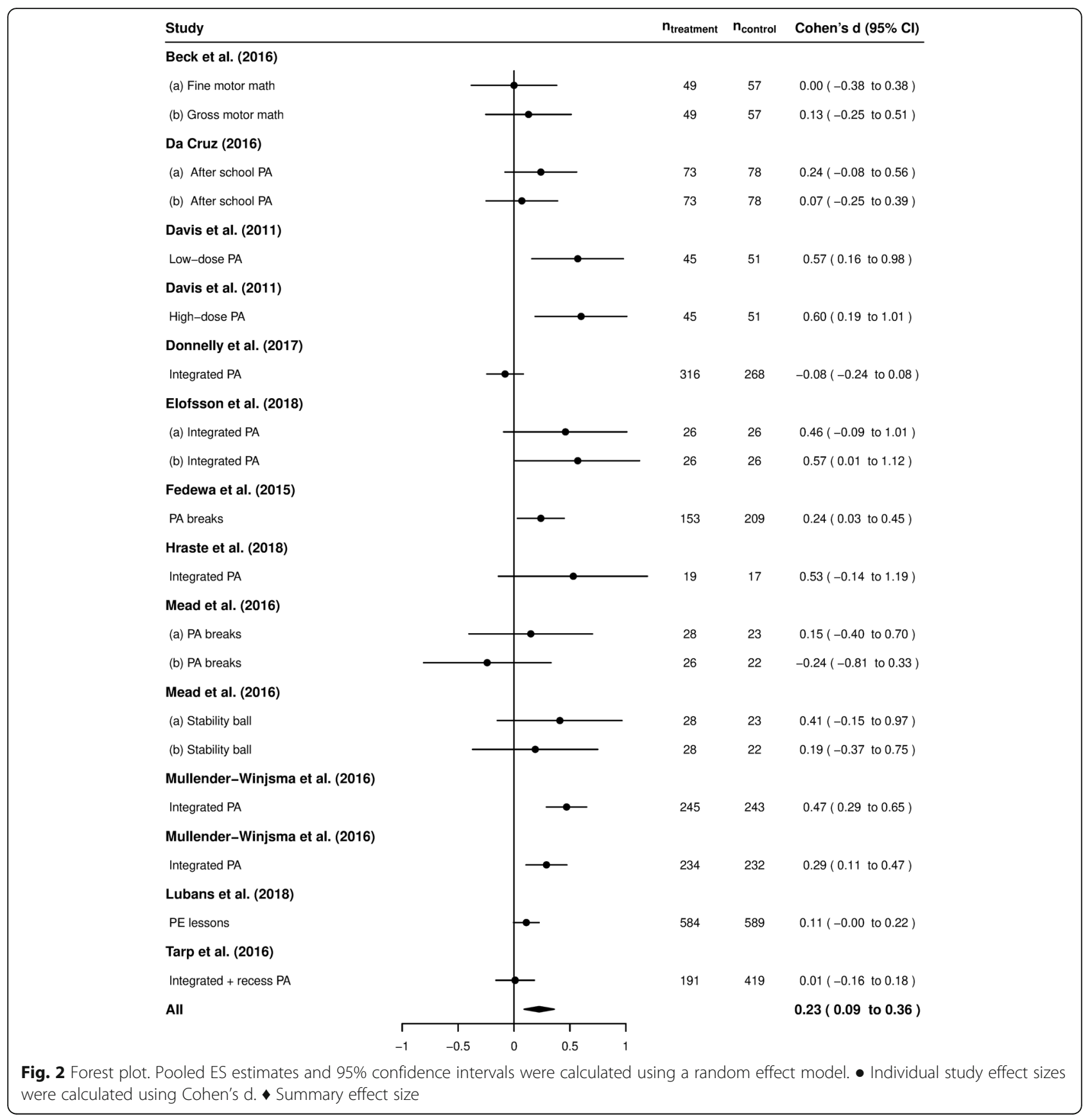

interventions included, for example, PA breaks, integrated PA, active transportation to school and PA homework. These interventions had no overall effect.

In four of the five studies investigating the acute effects of PA on math performance, PA sessions took place right before math performance testing sessions [61, 75-77]. The PA sessions lasted approximately $20-30 \mathrm{~min}$ and varied in intensity. Two of these studies indicated positive effects of PA sessions on math scores [61, 76] and two indicated neutral effects $[75,77]$ One of the acute effect studies employed 5-20-min breaks during math lessons
[9]. In this study, math scores proved to be higher after 10- and 20-min exercise breaks but not after 5-min breaks. See Table 1 for all the details.

In some of the reviewed PA interventions, additional findings were reported for subgroups of participants. Howie, Schatz and Pate [9] reported that classroom exercise breaks had a positive effect on mathematics scores for participants with lower IQ, higher aerobic fitness or lower school engagement. Beck and colleagues [40] reported that average mathematics performers (not low performers) benefited from math-related gross 
motor activities but not from fine motor activities. In a large Norwegian study [73] $(n=1129)$, subgroup analysis indicated positive intervention effects for pupils with the poorest math baseline scores. In a later analysis, a negative trend (not a significant effect) in mathematics performance was found for middle and high-performing girls [74]. In a study by Sjöwall [67] subgroup analyses revealed no favourable intervention effects for children with low baseline fitness or cognition.

\section{Results of meta-analysis}

Data for meta-analysis were available for 11 studies. Some of these studies included two different intervention conditions and/or two separate mathematics outcomes, thus leading to two to four different ES estimates for these studies. The results of the analysis are presented in Fig. 2. Small ESs $(0.2 \leq \mathrm{ES} \leq 0.5)$ were detected in six intervention studies. Moderate ESs $(\geq 0.5)$ were found for four interventions. One of the interventions indicated a small negative ES (-0.24) [59]. The rest indicated no effect $(-0.2 \leq \mathrm{ES}<0.2)$. Overall, on average a small positive effect $(\mathrm{d}=0.23)$ was found for all the interventions. The level of statistical heterogeneity between the intervention groups was high, $\mathrm{I}^{2}=69.6 \%$. In the moderator analysis, the age of participants $(\beta=-0.051, p=0.045)$ and the duration of intervention $(\beta=-0.003, p=0.002)$ were found to explain heterogeneity. The type of intervention was not found to influence ESs. See Table 2 for a full analysis.

\section{Results of risk-of-Bias assessment}

The results of the risk-of-bias assessment analysis are shown in Table 3. Of the 29 studies, 12 were rated as having a low risk of bias (>67\% of total score) and 17 were rated as having a moderate risk of bias (between 33 and $67 \%$ of the total score). None of the studies was rated as having a high risk of bias. Only eight studies reported power calculations to determine sufficient sample sizes. Of those reporting positive effects of PA on mathematics performance, power calculations were provided in five $[36,58,61,64,74]$.

\section{Discussion}

The purpose of this systematic review was to examine the effects of school-based PA interventions on children's mathematics performance and to detect and identify the features of effective interventions. The review indicated that $45 \%$ of the 29 intervention studies included in the analysis based on a rigorous literature search showed positive effects, and the meta-analysis of 11 studies suggested an overall small positive effect of school-based PA interventions on children's mathematics performance. Only one study indicated significant negative effects in a subgroup of participants. Taken together, the results of this review provide evidence to support the assumption that increasing school-based PA can have positive effects on children' mathematics performance and that it does not have harmful effects on performance. The findings seem to be in line with earlier reviews investigating academic performance in general $[6,16,17]$.

The moderator analysis revealed that older age of participants and longer duration of intervention were negatively associated with ESs. This suggests that younger children may benefit more from PA interventions than older children and that longer interventions are not necessarily more effective than shorter ones.

This review included various types of PA interventions - physically active mathematics lessons integrating PA into academic learning goals, the introduction of PA during or after school, adding short PA breaks during academic lessons or in the middle of the school day and bursts of activity right before mathematics testing. There was no clear evidence indicating that some of the types of PA would be more effective than the others. However, increasing the amount of traditional PE lessons did not seem to have a positive effect on mathematics learning, whereas PE lessons with more intense PA did make a difference. In their earlier review and meta-analysis Alvarez-Bueno and colleagues [17] concluded that curricular PE lessons seemed to be the most appropriate type of PA to improve children's academic achievement, although integrating PA in classroom lessons also benefited mathematics-related skills. Hence, drawing

Table 2 Moderator analysis

\begin{tabular}{llllllll}
\hline & $\beta$ & SE & t-value & df & $p$-value & $95 \%$ Cl Lower & $95 \%$ Cl Upper \\
\hline Age & -0.051 & 0.023 & -2.21 & 13 & 0.045 & -0.100 & -0.001 \\
Duration of intervention & -0.003 & 0.001 & -3.71 & 13 & 0.002 & -0.005 & -0.001 \\
$\begin{array}{l}\text { Type of intervention: } \\
\text { Extra PA }\end{array}$ & 0.090 & 0.138 & 0.652 & 13 & 0.525 & -0.208 & 0.388 \\
Integrated PA & 0.015 & 0.146 & 0.098 & 13 & 0.923 & -0.302 & 0.331 \\
PA breaks & -0.115 & 0.120 & -0.960 & 13 & 0.355 & -0.373 & 0.144 \\
Other & -0.108 & 0.113 & -0.950 & 13 & 0.359 & -0.353 & 0.137 \\
\hline
\end{tabular}




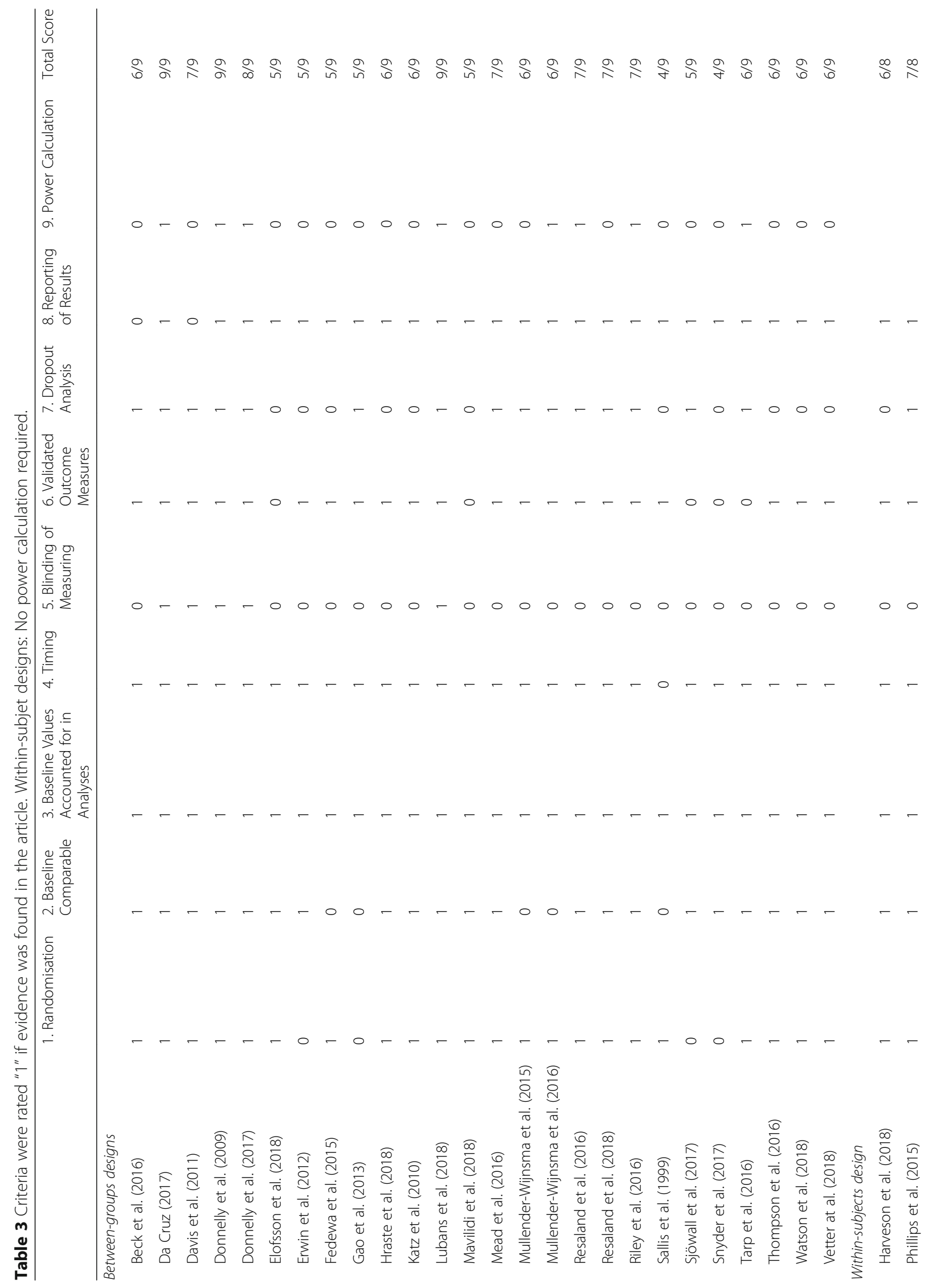




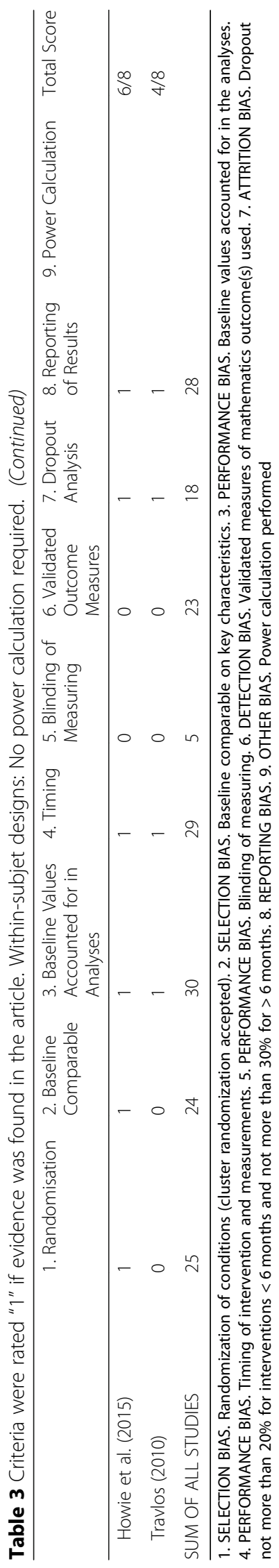


conclusions on what type of PA works best remains a challenge.

Subgroup analyses showed that students' cognitive abilities may have an effect on how much they benefit from increased PA with respect to math performance gains. Two studies [9, 74] suggested trends implying that children with lower IQ or baseline achievement and low school engagement may benefit more from PA interventions than other participants. Nonetheless, Beck and colleagues [40] reported conflicting results. Studies focusing on overweight children [68] and children with a minority background [70] reported some positive effects of PA on math performance. Although interpretations need to be made with caution, the analyses suggest that children experiencing barriers to learning might benefit more from increased amounts of PA in school than other children.

The findings of acute effect studies by Phillips and colleagues [61] and Travlos [76] indicated that the timing of PA during the school day may be important, thus providing support for the view that the placement of PA breaks before cognitively challenging tasks may be beneficial. The results of Howie and colleagues [9] suggested that 5-min PA breaks may be too short to have effects on math performance, whereas breaks lasting 10 or 20 min may have beneficial effects.

Many of the reviewed studies included measures of other outcomes, for example, measures of cognitive skills, executive functions, behaviour, brain activation and language achievement. Further examination of these factors in future studies would be helpful in determining how or why PA might affect mathematics performance. For instance, Beck and colleagues [40] have argued that favourable effects of motor activities on academic performance may be accounted for by changes in the visuospatial short-term memory and improved attentional resources. In the study by da Cruz [58] participation in a PA intervention was found to be positively associated with changes in both inhibition and mathematics fluency. Davis and colleagues [68] evidenced increased prefrontal cortex activity in study participants and suggested that cognitive changes might be the result of neural simulation rather than being mediated by cardiovascular benefits. The results of a study by Elofsson and colleagues [55] showed that children's motor skills explained almost $16 \%$ of the variation in mathematical measures.

Despite the positive effects shown in almost half of the reviewed interventions, it is unclear whether PA per se was the cause of those positive effects. For instance, Mullender-Wijnsma and colleagues [36] suggested that academic engagement or an innovative teaching method consisting of repetition and memorization techniques might partially explain the positive effects of their PA intervention. Although only designs with an intervention vs. control condition comparison were included in the review, alternative explanations for positive intervention effects cannot be ruled out. That is, it is possible that instead of or in addition to direct effects of increased PA, it was the attention from adults, a change in routine or pedagogical practices and increased engagement and enjoyment that produced the positive results. It is probable that children may experience psychological changes due to the social interaction that occurs during PA sessions [18]. These perspectives require further investigation.

Because some learners associate anxiety or dislike with mathematics lessons, it is relevant to note that some of the interventions integrating PA and mathematics reported positive experiences by teachers and students, and student engagement during lessons was also enhanced [78]. Learning activities that are engaging promote small group social interaction and de-emphasize competition, thus enhancing learning [45].

Three recent large-scale Scandinavian multicomponent interventions $[60,67,73]$ where various types of PA were added to the school day did not indicate significant positive effects on mathematics performance. This may be because Scandinavian school days already include regular breaks, weekly PE lessons and a pedagogy that activates children. This raises the question of whether there may be an upper limit after which the increased amount of PA no longer improves academic achievement. Nonetheless, the finding that academic performance is not harmed by additional PA is important because of the beneficial effects of PA on children's physical and mental health.

One of the strengths of this review is that only studies with baseline measures and control groups were accepted for analysis. Furthermore, only studies using random control trial designs were included in the meta-analysis. Studies with teacher-reported grades without any test scores were not included in the sample, as grades are often tied to local and national educational culture and curriculum. The risk-of-bias assessment was added to the analysis to provide information at the evidence level, and it revealed no studies with a high risk of bias.

There are some limitations to this study that must be noted. The number of high-quality studies on the topic is still low, which posed challenges, particularly as regards the meta-analysis. Missing data in the original articles or deficiencies in study designs reduced the pool of studies eligible for ES analysis, which might affect the strength of the conclusions. The large statistical heterogeneity of the results may reduce the reliability of the meta-analysis and hence the overall effects size should be interpreted with caution. On the whole, heterogeneity of the results may be due to different educational contexts, measures of mathematics performance and nature of PA 
selected for the intervention. Some methodological challenges were identified in the original studies, such as the lack of power calculations or evaluations of treatment fidelity. The commitment of participants was a factor that compromised interpretations in some of the studies [60]. Even though nationally used curriculum-based tests are needed, future studies should preferably utilize internationally acknowledged tests and task types for basic mathematical skills [56].

Despite the promising results, more replication studies with similar measurement, adequate sample sizes and carefully planned control groups are needed to establish a potential causal relationship between PA and academic performance [16, 29]. Regarding the theoretical basis upon which assumptions about the mechanisms behind the effects of PA can be drawn and tested, a clear need exists for merging neuroscientific, psychological or educational theorizing and concepts to better understand the mechanisms behind the effects of PA on children's academic performance. More research is needed to answer questions such as the extent to which we can reduce the time spent in sedentary activities and not compromise the academic learning of children.

Schools have a key role in introducing and integrating PA into children's everyday lives. Accordingly, every opportunity should be explored and made use of in the school curricula and pedagogical practices to diminish the harmful effects of a sedentary lifestyle. The information presented in this review and meta-analysis provides some evidence to back the supposition that adding more PA to the school day and to lessons in the form of PA breaks, extra PA sessions, more intense PE lessons or PA integrated into academic lessons may enhance children's academic performance and mathematics learning. The results of this systematic review and further studies can help convince educators and policy makers to recommend the addition and effective integration of PA into the school day.

\section{Supplementary information}

Supplementary information accompanies this paper at https://doi.org/10. 1186/s12966-019-0866-6.

Additional file 1: Systematic search strategy.

\section{Abbreviations}

ES: Effect size; M: Mean value; MBESS: Methods for the Behavioral, Educational, and Social Sciences; MVPA: Moderate to vigorous physical activity; PA: Physical activity; PE: Physical education

\section{Acknowledgements}

None to report.

\section{Authors' contributions}

SS, HS and TT designed the study. SS, TT, HV and A-MP developed the search strategy and SS conducted the search. SS, TT, HV, HS and A-MP screened studies for inclusion. SS and HS extracted the data and conducted the risk of bias assessment. AK, $\mathrm{HH}$ and SS conducted the meta-analysis. SS drafted the manuscript and SS, TT, HS, HV and A-MP contributed to the final manuscript. All authors read and approved the final manuscript.

\section{Funding}

The study is funded by the Ministry of Education and Culture, Finland. OKM/ 79/626/2018.

\section{Availability of data and materials}

Most of the data generated or analysed during this study are included in this published article and its supplementary information files, or in the published original articles included in the review. A small amount of data (math test means missing in the included original articles) were received directly from original authors and are available on request from the corresponding author.

Ethics approval and consent to participate

Not applicable.

Consent for publication

Not applicable.

\section{Competing interests}

The authors declare that they have no competing interests.

\section{Author details}

${ }^{1}$ LIKES Research Centre for Physical Activity and Health, Rautpohjankatu 8, 40700 Jyväskylä, Finland. 'Faculty of Education, University of Oulu, Oulu, Finland. ${ }^{3}$ Department of Education and Psychology, University of Jyväskylä, Jyväskylä, Finland. ${ }^{4}$ Faculty of Education and Psychology, University of Jyväskylä, Jyväskylä, Finland.

Received: 21 May 2019 Accepted: 21 October 2019

Published online: 21 November 2019

\section{References}

1. 2018 Physical Activity Guidelines Advisory Committee. 2018 Physical Activity Guidelines Advisory Committee Scientific Report. 2018 Physical activity guidelines advisory committee scientific report. Washington, DC: U.S. Department of Health and Human Services; 2018.

2. Janssen I, LeBlanc AG, Janssen I, Twisk J, Tolfrey K, Jones A, et al. Systematic review of the health benefits of physical activity and fitness in school-aged children and youth. Int J Behav Nutr Phys Act. 2010;7(1):40.

3. Lubans D, Richards J, Hillman C, Faulkner G, Beauchamp M, Nilsson M, et al. Physical activity for cognitive and mental health in youth: a systematic review of mechanisms. Pediatrics. 2016;138(3):-e20161642.

4. Dishman RK, Hales DP, Pfeiffer KA, Felton GA, Saunders R, Ward DS, et al. Physical self-concept and self-esteem mediate cross-sectional relations of physical activity and sport participation with depression symptoms among adolescent girls. Health Psychol. 2006;25(3):396-407.

5. Singh A, Twisk JWR, Van Mechelen W, Chinapaw MJM, Central C. Physical activity and performance at school. Arch Pediatr Adolesc Med. 2012;166(1): 49-55.

6. Donnelly JE, Hillman CH, Castelli D, Etnier JL, Lee S, Tomporowski P, et al. Physical activity, fitness, cognitive function, and academic achievement in children: a systematic review. Med Sci Sports Exerc. 2016:48(6):1197-222

7. Kari JT, Pehkonen J, Hutri-Kähönen N, Raitakari OT, Tammelin TH. Longitudinal associations between physical activity and educational outcomes. Med Sci Sport Exerc. 2017;33:1.

8. Tremblay MS, Gonzalez SA, Katzmarzyk PT, Onywera VO, Reilly JJ, Tomkinson G. Introduction to the Global Matrix 2.0: report card grades on the physical activity of children and youth comparing 38 countries. J Phys Act Health. 2016;13(11 Suppl 2):S85-6.

9. Howie EK, Schatz J, Pate RR. Acute effects of classroom exercise breaks on executive function and math performance: a dose-response study. Res Q Exerc Sport. 2015 Jul 3;86(3):217-24.

10. Riley N, Lubans DR, Holmes K, Morgan PJ. Findings from the EASY minds cluster randomized controlled trial: evaluation of a physical activity integration program for mathematics in primary schools. Orig Res J Phys Act Heal. 2016;13:198-206.

11. World Health Organization. Global recommendations on physical activity for health, vol. 60. Geneva: World Heal Organ; 2010. 
12. Aubert S, Barnes JD, Abdeta C, Nader PA, Adeniyi AF, Tenesaca DSA, et al. Global Matrix 3 . 0 Physical Activity Report Card Grades for Children and Youth : Results and Analysis From 49 Countries. J Phys Act Heal. 2018; 15(Suppl 2).

13. Carlson JA, Sallis JF, Norman GJ, McKenzie TL, Kerr J, Arredondo EM, et al. Elementary school practices and children's objectively measured physical activity during school. Prev Med (Baltim). 2013;57(5):591-5.

14. Themanson JR, Pontifex MB, Hillman CH. Fitness and action monitoring: evidence for improved cognitive flexibility in young adults. Neuroscience. 2008 Nov;157(2):319-28.

15. Resaland GK, Anderssen SA, Holme IM, Mamen A, Andersen LB. Effects of a 2-year school-based daily physical activity intervention on cardiovascular disease risk factors: the Sogndal school-intervention study. Scand J Med Sci Sports. 2011;21:e122-31.

16. Singh AS, Saliasi E, Van Den Berg V, Uijtdewilligen L, De Groot RHM, Jolles J, et al. Effects of physical activity interventions on cognitive and academic performance in children and adolescents: a novel combination of a systematic review and recommendations from an expert panel. $\mathrm{Br} J$ Sports Med. 2018:1-10

17. Álvarez-Bueno C, Pesce C, Cavero-Redondo, Ivan Sánchez-López M, GarridoMiguel M, Martínez-Vizcaíno V. Academic achievement and physical activity : a meta-analysis. Pediatrics. 2017;140(6):e20171498.

18. Davis CL, Cooper S. Fitness, fatness, cognition, behavior, and academic achievement among overweight children: do cross-sectional associations correspond to exercise trial outcomes? Prev med (Baltim). NIH Public Access. 2011 Jun;52(Suppl 1):S65-9.

19. Drollette ES, Scudder MR, Raine LB, Moore RD, Saliba BJ, Pontifex MB, et al. Acute exercise facilitates brain function and cognition in children who need it most: an ERP study of individual differences in inhibitory control capacity. Dev Cogn Neurosci. 2014;7:53-64.

20. Hillman $\mathrm{CH}$, Erickson Kl, Kramer AF. Be smart, exercise your heart: exercise effects on brain and cognition. Nat Rev Neurosci. 2008 Jan;9(1):58-65.

21. Gomez-Pinilla F, Hillman $\mathrm{CH}$. The influence of exercise on cognitive abilities. Compr Physiol. 2013;3(1):403-28.

22. Berse T, Bissonette GB, Petzinger G, Totah NK, Rolfes K, Barenberg J, et al. Acute physical exercise improves shifting in adolescents at school: evidence for a dopaminergic contribution. Front Behav Neurosci. 2015;9:1-9.

23. Chaddock-Heyman L, Erickson K, Voss M, Knecht A, Pontifex M, Castelli D, et al. The effects of physical activity on functional MRI activation associated with cognitive control in children: a randomized controlled intervention. Front Hum Neurosci. 2013;7:72.

24. Diamond A. Executive functions. Annu Rev Psychol Annual Reviews. 2013 Jan 2;64(1):135-68

25. Jacob R, Partkinson J. The potential for school-based interventions that target executive function to improve academic achievement: a review. Rev Educ Res. 2015:41(4):41.

26. Grieco LA, Jowers EM, Errisuriz VL, Bartholomew JB. Physically active vs. sedentary academic lessons: a dose response study for elementary student time on task. Prev Med (Baltim). 2016:89:98-103.

27. Carlson JA, Engelberg JK, Cain KL, Conway TL, Mignano AM, Bonilla EA, et al. Implementing classroom physical activity breaks: associations with student physical activity and classroom behavior. Prev Med (Baltim). 2015 Dec;81:67-72.

28. Owen KB, Parker PD, Van Zanden B, MacMillan F, Astell-Burt T, Lonsdale C. Physical activity and school engagement in youth: a systematic review and meta-analysis. Educ Psychol. 2016;51(2):129-45.

29. Daly-smith AJ, Zwolinsky S, Mckenna J, Tomporowski PD, Defeyter MA, Manley A. Systematic review of acute physically active learning and classroom movement breaks on children's physical activity, cognition , academic performance and classroom behaviour : understanding critical design features. BMJ Open Sport Exerc Med. 2018;4:e000341.

30. Jaakkola T, Hillman C, Kalaja S, Liukkonen J. The associations among fundamental movement skills, self-reported physical activity and academic performance during junior high school in Finland. Med Sci Sport Exerc. 2015:33(16):1719-29.

31. Kantomaa MT, Stamatakis E, Kankaanpää A, Kaakinen M, Rodriguez A, Taanila A, et al. Physical activity and obesity mediate the association between childhood motor function and adolescents' academic achievement. Proc Natl Acad Sci U S A. 2013 Jan 29:110(5):1917-22.

32. Haapala EA, Poikkeus A, Tompuri T, Kukkonen-harjula K, Leppa PHT. Associations of motor and cardiovascular performance with academic skills in children. Med Sci Sport Exerc. 2014;46(38):1016-24.
33. Zhang X, Räsänen P, Koponen T, Aunola K, Lerkkanen MK, Nurmi JE. Knowing, applying, and reasoning about arithmetic: roles of domaingeneral and numerical skills in multiple domains of arithmetic learning. Dev Psychol. 2017:53(12):2304-18.

34. Lowrie T, Logan T, Ramful A. Visuospatial training improves elementary students' mathematics performance. Br J Educ Psychol. 2017:87(2):170-86.

35. Peng P, Wang C, Namkung J. Understanding the cognition related to mathematics difficulties: a meta-analysis on the cognitive deficit profiles and the bottleneck theory. Rev Educ Res. 2018;88(3):434-76.

36. Mullender-Wijnsma MJ, Hartman E, de Greeff JW, Doolaard S, Bosker RJ, Visscher C. Physically active math and language lessons improve scademic schievement: a cluster randomized controlled trial. Pediatrics. 2016;137(3): e20152743.

37. Mullender-Wijnsma H. E, de Greeff JW, Bosker RJ, Doolaard S, Visscher C improving academic performance of school-age children by physical activity in the classroom: 1-year program evaluation. J Sch Health. 2015; 85(6):365-71.

38. Van der Beek JPJ, Van der Ven SHG, Kroesbergen EH, Leseman PPM. Selfconcept mediates the relation between achievement and emotions in mathematics. Br J Educ Psychol. 2017;87(3):478-95.

39. Sorvo R, Koponen $T$, Viholainen $H$, Aro T, Räikkönen E, Peura P, et al. Math anxiety and its relationship with basic arithmetic skills among primary school children. Br J Educ Psychol. 2017;87(3):309-27.

40. Beck MM, Lind RR, Geertsen SS, Ritz C, Lundbye-Jensen J. Motor-Enriched Learning Activities Can Improve Mathematical Performance in Preadolescent Children. Artic Front Hum Neurosci. 2016;10(10).

41. Kennedy J, Lyons T, Quinn F. The continuing decline os science and mathematics enrolments in Australian high schools. Teach Sci. 2014;60(2):34-46.

42. Stokke A. What to Do about Canada's Declining Math Scores [Internet]. 2015 [cited 2018 Apr 4]. Available from: www.cdhowe.org.

43. Tuohilampi L, Hannula MS, Laine A. Examining mathematics-related affect and its development during comprehensive school years in Finland. In: Proceedings of the joint meeting of PME 38 and PME-NA 36. Vancouver: PME; 2014. p. 281-8

44. Higgins J, Green S (editors). Cochrane Handbook for Systematic Reviews of Interventions Version 5.1.0 [Internet]. The Cochrane Collaboration; 2011 [cited 2018 Apr 15]. Available from: www.handbook.cochrane.org.

45. Martin R, Murtagh EM. Effect of active lessons on physical activity, academic and health outcomes: a systematic review. Res Q Exerc Sport Routledge. 2017:88(2):1-20.

46. Lonsdale C, Rosenkranz RR, Peralta LR, Bennie A, Fahey P, Lubans DR. A systematic review and meta-analysis of interventions designed to increase moderate-to-vigorous physical activity in school physical education lessons. Prev Med (Baltim). 2013:56(2):152-61.

47. van Sluijs EMF, McMinn AM, Griffin SJ. Effectiveness of interventions to promote physical activity in children and adolescents: systematic review of controlled trials. Bmj. 2007;335(7622):703.

48. Dong N, Maynard RA. PowerUp! A tool for calculating minimum detectable effect sizes and sample size requirements for experimental and quasiexperimental designs. J Res Educ Eff. 2013;6(1):24-67.

49. Viechtbauer $\mathbf{W}$. Conducting meta-analyses in $\mathrm{R}$ with the metafor package. J Stat Softw. 2010;36(3):1-48.

50. Higgins JPT, Thompson SG. Quantifying heterogeneity in a meta-analysis. Stat Med. 2002;21(11):1539-58.

51. Cohen J. A power primer. Psychol Bull. 1992;112(1):155-9.

52. Zhu W. $P<0.05,<0.01,<0.001,<0.0001,<0.00001,<0.000001$, or t... J Sport Heal Sci. 2016;5(1):77-9.

53. Kelley K. Confidence Intervals for Standardized Effect Sizes : J Stat Softw. 2007:20(8):1-24

54. Mavilidi MF, Okely A, Chandler P, Louise Domazet S, Paas F. Immediate and delayed effects of integrating physical activity into preschool children's learning of numeracy skills. J Exp Child Psychol. 2018;166:502-19.

55. Elofsson J, Englund Bohm A, Jeppsson C, Samuelsson J. Physical activity and music to support pre-school children's mathematics learning. Education 3-13. 2018:46(5):483-93.

56. Erwin H, Fedewa A, Ahn S. Student academic performance outcomes of a classroom physical activity intervention: a pilot study. Int Electron J Elem Educ. 2012;4(3):473-87.

57. Katz DL, Cushman D, Reynolds J, Njike V, Treu JA, Walker J, et al. Putting physical activity where it fits in the school day: preliminary results of the 
$A B C$ (activity bursts in the classroom) for fitness program. Prev Chronic Dis. 2010;7(4):1-10.

58. da Cruz K. Effects of a randomised trial after-school physical activity Club on the math achievement and executive functioning of girls. Michigan State University: ProQuest Dissertations Publishing; 2017. https://search.proquest. com/openview/90db9eb6aa05a5794c38c10874029006/1?pq-origsite= gscholar\&cbl=18750\&diss $=y$.

59. Mead T, Scibora L, Gardner J, Dunn S. The impact of stability balls, activity breaks, and a sedentary classroom on standardized math scores. Phys Educ. 2016;73(3):433-49.

60. Tarp J, Domazet SL, Froberg K, Hillman CH, Andersen LB, Bugge A. Effectiveness of a school-based physical activity intervention on cognitive performance in Danish adolescents: LCoMotion-learning, cognition and motion - a cluster randomized controlled trial. PLoS One. 2016;11(6):1-19.

61. Phillips D, Hannon JC, Castelli DM. Effects of vigorous intensity physical activity on mathematics test performance. J Teach Phys Educ. 2015 Jul;34(3): $346-62$

62. Hraste M, De Giorgio A, Jelaska PM, Padulo J, Granić I. When mathematics meets physical activity in the school-aged child: the effect of an integrated motor and cognitive approach to learning geometry. PLoS One. 2018;13(8): $1-14$.

63. Donnelly JE, Greene JL, Gibson CA, Smith BK, Washburn RA, Sullivan DK, et al. Physical activity across the curriculum (PAAC): a randomized controlled trial to promote physical activity and diminish overweight and obesity in elementary school children. Prev Med (Baltim). 2009;49(4):336-41.

64. Donnelly JE, Hillman CH, Greene JL, Hansen DM, Gibson CA, Sullivan DK, et al. Physical activity and academic achievement across the curriculum: Results from a 3-year cluster-randomized trial. Prev Med (Baltim). 2017; 99(Supplement C):140-5.

65. Snyder K, Dinkel D, Schaffer C, Hiveley S, Colpitts A. Purposeful movement: the integration of physical activity into a mathematics unit. Int J Res Educ Sci. 2017;3(1):75-87.

66. Vetter M, O'Connor H, O'Dwyer N, Orr R. Learning "math on the move": effectiveness of a combined numeracy and physical activity program for primary school children. J Phys Act Health. 2018;15(7):492-8.

67. Sjöwall D, Hertz M, Klingberg T. No long-term effect of physical activity intervention on working memory or arithmetic in preadolescents. Front Psychol. 2017;8:1-10.

68. Davis CL, Tomporowski PD, McDowell JE, Austin BP, Miller PH, Yanasak NE, et al. Exercise improves executive function and achievement and alters brain activation in overweight children: a randomized. Controlled Trial Heal Psychol. 2011;30(1):91-8.

69. Lubans DR, Beauchamp MR, Diallo TMO, Peralta LR, Bennie A, White RL, et al. School physical activity intervention effect on adolescents' performance in mathematics. Med Sci Sports Exerc. 2018;50(12):2442-50.

70. Gao Z, Hannan P, Xiang P, Stodden DF, Valdez VE. Video game-based exercise, Latino children's physical health, and academic achievement. Am J Prev Med. 2013 Mar;44(3 Suppl 3):S240-6.

71. Fedewa AL, Ahn S, Erwin H, Davis MC. A randomized controlled design investigating the effects of classroom- based physical activity on children's fluid intelligence and achievement. Sch Psychol Int. 2015;36(21):135-53.

72. Watson AJL, Timperio A, Brown H, Hesketh KD. A pilot primary school active break program (ACTI-BREAK): Effects on academic and physical activity outcomes for students in Years 3 and 4. J Sci Med Sport. Sports Medicine Australia. 2019:22(4):438-43.

73. Resaland GK, Aadland E, Moe VF, Aadland KN, Skrede T, Stavnsbo M, et al. Effects of physical activity on schoolchildren's academic performance: The Active Smarter Kids (ASK) cluster-randomized controlled trial. Prev Med (Baltim). 2016;91:322-8.

74. Resaland GK, Moe VF, Bartholomew JB, Andersen LB, McKay HA, Anderssen $S A$, et al. Gender-specific effects of physical activity on children's academic performance: The Active Smarter Kids cluster randomized controlled trial. Prev Med (Baltim). 2018;106:171-6.

75. Thompson HR, Duvall J, Padrez R, Rosekrans N, Madsen KA. The impact of moderate-vigorous intensity physical education class immediately prior to standardized testing on student test-taking behaviors. Ment Health Phys Act. 2016;11(Supplement C):7-12.

76. Travlos AK. High intensity physical education classes and cognitive performance in eighth-grade students: an applied study. Int J Sport Exerc Psychol. 2010;8(3):302-11.
77. Harveson A, Hannon J, Brusseau T, Podlog L, Chase B, Kang K. Acute Exercise and Academic Achievement in High School Youth. Physical Educator. 2018;75(1):25-36.

78. Riley N, Lubans D, Holmes K, Hansen V, Gore J, Morgan P. Movement-based mathematics: enjoyment and engagement without compromising learning through the EASY minds program. Eurasia J Math Sci Technol Educ. 2017; 13(6):1653-73.

\section{Publisher's Note}

Springer Nature remains neutral with regard to jurisdictional claims in published maps and institutional affiliations.
Ready to submit your research? Choose BMC and benefit from:

- fast, convenient online submission

- thorough peer review by experienced researchers in your field

- rapid publication on acceptance

- support for research data, including large and complex data types

- gold Open Access which fosters wider collaboration and increased citations

- maximum visibility for your research: over $100 \mathrm{M}$ website views per year

At BMC, research is always in progress.

Learn more biomedcentral.com/submissions 